\title{
INFLUENCE OF FITNESS TECHNIQUES INTEGRATION ON THE DEVELOPMENT OF PHYSICAL QUALITIES AND MORPHO-FUNCTIONAL STATE OF ADULT FEMALES
}

original paper

(1) University School of Physical Education in Wroclaw

DOI: https://doi.org/10.5114/hm.2021.98465

\section{OLEKSANDR MOZOLEV ${ }^{1}$, IHOR BLOSHCHYNSKYI ${ }^{2}$, KOSTIANTYN PRONTENKO $^{3}$,} LARYSA ZDANEVYCH ${ }^{4}$, KATERYNA KRUTY $^{5}$, OKSANA POPOVYCH ${ }^{6}$, LEONIDA PISOTSKA $^{7}$

${ }^{1}$ Department of Theory and Methodology of Physical Culture and Valeology, Khmelnytskyi Humanitarian-Pedagogical Academy, Khmelnytskyi, Ukraine

${ }^{2}$ Foreign Languages Department, Bohdan Khmelnytskyi National Academy of the State Border Guard Service of Ukraine, Khmelnytskyi, Ukraine

${ }^{3}$ Department of Physical Education, Special Physical Training and Sport, S.P. Koroliov Zhytomyr Military Institute, Zhytomyr, Ukraine

${ }^{4}$ Department of Pre-school Pedagogy, Psychology and Professional Methods, Khmelnytskyi Humanitarian-Pedagogical Academy, Khmelnytskyi, Ukraine

${ }^{5}$ Department of Pre-school and Primary Education, Vinnytsia Mykhailo Kotsiubynskyi State Pedagogical University, Vinnytsia, Ukraine

${ }^{6}$ Department of Theory and Methodology of Pre-school Education, Mukachevo State University, Mukachevo, Ukraine

${ }^{7}$ Faculty of Pre-school Pedagogy, Khmelnytskyi Humanitarian-Pedagogical Academy, Khmelnytskyi, Ukraine

\begin{abstract}
Purpose. The article focuses on the influence of recreational fitness exercises on the level of adult females' physical qualities and morpho-functional state development.

Methods. Overall, 32 women aged 30-45 years took part in the research, based on the authors' program combining various types of fitness exercise. One-hour workouts were conducted 2 times per week at Khmelnytskyi Humanitarian-Pedagogical Academy for 9 months. The morpho-functional state of the participants was determined by measuring their height, weight, lung capacity, heart rate, arterial blood pressure, body parts circumferences, and skin folds. The level of physical qualities development was assessed with the following tests: sitting forward bend, running in place for 10 seconds, rope skipping for 30 seconds, bench push-ups for 30 seconds, sit-ups for 30 seconds, plank exercise, maintaining balance while standing on one leg.

Results. A confirmed improvement of the morpho-functional state indicators and physical qualities development of the participants of the pedagogical experiment $(p<0.05)$ was established. The most significant effect referred to body mass decrease, enhancement of cardiorespiratory system functional capabilities, as well as improvement of power and coordination abilities. Conclusions. The implemented authors' program, combining different types of fitness exercise, made the workouts flexible and varied, allowed to find an individual approach to each woman, and thus contributed to an increase of their physical condition by improving the morpho-functional state of the body and the level of physical health.
\end{abstract}

Key words: fitness techniques, morpho-functional state, physical qualities, adult females

\section{Introduction}

Maintaining the health and quality of life of adult females is an urgent issue of today because adulthood is the longest and most productive period of their lives. At this age, women are at the peak of their professional career, which is often associated with a decrease in motor activity, increase in the occurrence of stressful situations, and deterioration of health.

A certain rate of motor activity is required for the normal functioning of an adult's body. The former also depends on the physiological, socio-economic, and cul-

Correspondence address: Ihor Bloshchynskyi, Foreign Languages Department, Bohdan Khmelnytskyi National Academy of the State Border Guard Service of Ukraine, 46, Shevchenko Str., 29000, Khmelnytskyi, Ukraine, e-mail: i.bloshch@gmail.com

Received: June 14, 2019

Accepted for publication: January 24, 2020

Citation: Mozolev O, Bloshchynskyi I, Prontenko K, Zdanevych L, Kruty K, Popovych O, Pisotska L. Influence of fitness techniques integration on the development of physical qualities and morpho-functional state of adult females. Hum Mov. 2021;22(1):57-65; doi: https://doi.org/10.5114/hm.2021.98465. 
tural factors: age, sex, physical state, lifestyle, working, living, geographical and climatic conditions, etc. Determining the balanced norm of motor activity, related to the individual physical and physiological characteristics of adult females, as well as observing these norms allow women to conduct active professional, social, cultural, and family life. Excess weight is characteristic of adult females and results from sedentary lifestyle, life stress, or having given birth to children. Therefore, there is a need to develop an authors' program of corrective training, which would include breathing exercises, stretching exercises, strengthening the abdominal muscles, exercises for the development of the hip joints, and many other exercises having a positive effect on the female body as a whole. The selection of exercises in this experimental study was based on the characteristics of the adult female body, particularly in the premenopausal period, which also influences women's physical level.

At the present stage of the society development, an increasing number of adult females become engaged in popular sports exercises, namely fitness, to maintain their physical condition and health. Overall fitness fosters good quality of life, combining social, mental, spiritual, and physical factors [1]. Fitness is a chance to change the quality of life without any excessive effort; it includes the most advanced training systems that cover the most effective techniques for improving body and posture [2]. The health-improving effect of fitness is associated with increased physical activity, strengthening the musculoskeletal, cardiovascular, and respiratory system function, activation of metabolism, and a decrease in body weight $[3,4]$.

In our research, recreational fitness is understood as a type of physical culture which aims at improving the general state of the human body and its readiness to respond to negative environmental factors by doing both simple and combined physical exercises.

By functional fitness we mean specialized training of the musculoskeletal, cardiovascular and respiratory systems of the human body, as well as a set of measures that provide diverse physical development of a person, body control ability, well-being improvement, nutrition and healthy lifestyle formation.

The concept of corrective fitness encompasses purposeful training of separate muscle groups in order to change the body proportions.

The hypothesis of the research was that a complex combination of modern general physical fitness techniques that involve Pilates, shaping, and stretching as integral parts of each lesson conducted twice a week for up to 1 hour would increase the level of physical health, well-being, and physical qualities development in females aged 30-45 years.

The aim of the study was to investigate the effectiveness of the authors' program of physical and recreational exercises based on a rational combination of different types of fitness, as well as its impact on the level of physical health, well-being, functional capabilities, and the development of physical qualities in females aged $30-45$ years.

The tasks of the research were to establish the motivational and value-related orientations of adult females in relation to the necessity of taking up fitness; to assess the level of physical health of women at each phase of the pedagogical experiment; to check the development of morpho-functional abilities and physical qualities of women by using a system of tests; to analyse the impact of the elaborated program on the level of physical health, functional capabilities, wellbeing, and development of physical qualities.

\section{Material and methods}

\section{Participants}

A total of 32 women aged 30-45 years were divided into groups in accordance to their self-assessment of the level of health, physical condition, and motivation for fitness exercises.

\section{Design and methods}

The research was carried out in Khmelnytskyi Humanitarian-Pedagogical Academy and Evminov Center (Khmelnytskyi, Ukraine) among female participants aged 30-45 years, from September 2017 until June 2018.

The study was performed in accordance with the developed authors' program of organizing fitness sessions with adult females based on the research of the methodology of conducting various types of fitness exercises [5, 6]. Each session was held individually or in a group of not more than 3 people and constituted a set of interrelated components having a defined procedure, which considered the process of interaction in order to improve the functional and physical condition and obtain a health-improving effect [7].

During the first phase (3 months), the main attention was paid to general developmental exercises, which were health-oriented and gradually prepared the women's body for further loads. In the second phase (3 months), emphasis was put on the training of the body functional systems: cardiovascular, respiratory, and musculoskeletal. In the third phase (3 months), 
exercises were selected that aimed at changing the proportions of the body.

Taking into account the determined motivation of the adult females for fitness, we needed to organize training activities to achieve the following results: health improvement, functional performance increase, body shape and weight correction, physical condition and aesthetic appeal level increase.

The program of training sessions (workouts), developed by us, included 3 phases:

1. Health-improving (recreational) workout. The task of this phase was to develop flexibility and coordination of movements, strengthen the pectoral girdle, and prepare the body functional systems for future work by gradually increasing the load during the workout sessions.

2. Functional workout. This phase aimed to increase functional capabilities, primarily those of the cardiopulmonary and musculoskeletal systems, to strengthen skeletal and respiratory muscles, to develop overall strength, to improve the functional state of external respiration and the oxygen transportation system as a whole.

3. Corrective workout. The purpose of this phase was to change the body shape, to correct the figure taking into account the morpho-functional characteristics of the women, as well as to improve their physical condition and working capacity.

The first phase of the workout program was mainly focused on exercises for movement coordination, balance, and spine stretching, performed at a slow pace with no ballistic movements. Much attention was paid to breathing and posture control.

Aerobic exercises (dancing, walking, jogging, etc.) and various exercises improving balance, coordination, strength, and endurance were performed predominantly during the second phase of the program. The aerobic load was aimed at strengthening the cardiovascular system, improving posture, developing endurance, and normalizing the body fat percentage. Heart rate was maintained within the range of 130-150 beats per minute.

Exercise selection for the third phase depended on the state of the muscle groups of particular body parts. Power development exercises were focused on working out certain muscle groups. The load and duration of the rest intervals between repetitions considered the individual features of the females' muscle tissue and the desired effect of the workout. Exercises for movement coordination, balance, and spine stretching were mandatory and constituted important elements of both the preparatory and final parts of the workout.
To obtain the necessary information, we used general scientific methods of the theoretical research level: scientific and methodological source analysis, axiological analysis, pedagogical modelling, pedagogical experiment, pedagogical observation, methods of mathematical statistics.

The analysis of scientific and methodological sources was applied to study the current state of scientific viewpoints on the problem of engaging adult females in doing physical exercises, defining the requirements for fitness sessions arrangement. Axiological analysis served to determine the system of values of the subjects and their motivation for exercise. Pedagogical modelling helped develop the experimental versions of the healthimproving fitness training content, with the consideration of the information received on the functional and physical status of the subjects, as well as current information on morpho-functional and anthropometric changes, health status, and functional characteristics of the heart [8]. The methods of mathematical statistics allowed to accurately determine the level of development of motor and morpho-functional abilities of the adult females.

At each phase of the pedagogical experiment, we evaluated the morpho-functional state of the participants by using the express method [9], which provided results in the form of the following indicators:

- vital index (characterizes the functioning of the respiratory system);

- Robinson's index (quantitative estimation of a person's energy potential);

- Ruffier-Dickson's index (heart capacity testing);

- Stange's test (respiratory system assessment);

- body mass index (human body weight to height relationship).

Anthropometric measurements of the body circumferences are important to diagnose adult females' physical development. The crucial girths are those of the chest, waist, thigh, hip, and neck. Anthropometric measurements of skin folds are significant to control the state of the human endocrine system, the optimal use of food, and the sufficiency of physical activity. These measurements determine the fat percentage in the human body, fat to weight ratio. The anthropometric examinations of the adult females allowed to determine not only the required changes in body proportions, but also the changes in the skin folds at 3 sites (abdomen, lower angle of the shoulder blade, front of the thigh) to establish the somatic health level, to provide general assessment of the functional capacity and physical condition, and, finally, to develop an individual workout plan. 
To determine the level of somatic health in the course of fitness exercises, we measured the following anthropometric and physiometric indicators: waist girth, hip girth, abdominal girth, bust girth, skin folds, body weight, lung capacity, heart rate, arterial blood pressure. The anthropometric and physiometric indicators were established with the participation of a medical practitioner of a sports recreational centre by using the following tools: scales, stopwatch (heart rate), caliper (skin folds), spirometer (lung capacity), tonometer (arterial blood pressure).

Physical condition testing was carried out at the beginning of the experiment and at the end of the third, sixth, and ninth months of training. A system of tests was applied that allowed to assess the basic physical, functional, and coordination abilities of the participants. The test system included:

- sitting forward bend (flexibility);

- running in place for 10 seconds (speed);

- rope skipping for 30 seconds (speed endurance);

- bench push-ups for 30 seconds (power);

- sit-ups for 30 seconds (speed and power abilities);

- plank exercise (strength endurance);

- standing on one leg, arms extended sideways (coordination abilities).

\section{Statistical analysis}

During the research, the significance of differences between the indicators at the beginning and at the end of the experiment was determined by means of Student's $t$-test. The statistical significance of the results was set at $p<0.05$. All statistical analyses were performed with the SPSS software, version 21, adapted to medical and biological research.

\section{Ethical approval}

The research related to human use has complied with all the relevant national regulations and institutional policies, has followed the tenets of the Declaration of Helsinki, and has been approved by the authors' institutional review board or an equivalent committee.

\section{Informed consent}

Informed consent has been obtained from all individuals included in this study.

\section{Results}

Values are multifaceted socio-psychological phenomena which combine the goal and motivation orientation of a person's activity. To establish the values of

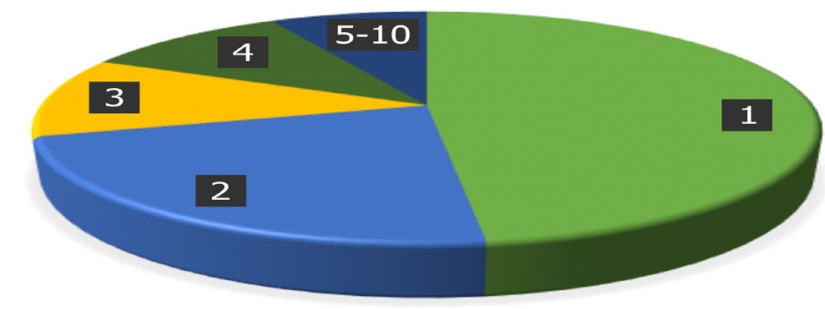

1 - health improvement (48.0\%), 2 - aesthetic appeal (22.7\%), 3 - selfconfidence (11.2\%), 4 - happy family life (10.3\%), 5 - active lifestyle $(2.3 \%)$, 6 - harmonious development (2.0\%), 7 - public importance $(1.5 \%)$,

8 - productive professional activity (1.0\%), 9 - entertainment and pastime $(0.7 \%), 10$ - search for new impressions and friends $(0.3 \%)$

Figure 1. Distribution of the values of adult females willing to do fitness exercises

the adult females who wanted to take up fitness, we asked them to make a choice based on 10 questions and to rank the importance of 3 factors [10], which determined their need for doing physical and recreational exercises (Figure 1).

According to the self-assessment survey on the state of the subjects' health, conducted at the beginning of the experiment, the level of physical health was high in 2 women, above average in 5 , average in 9, below average in 11, and low in 5 . The self-assessment testing results on the state of physical health depending on the experiment phase are presented in Table 1.

It should be noted that all the respondents reported improvement in their health status. Furthermore, the sum of the physical health level scores which determined the transition from one level to another was noted by 20 respondents (62.5\%). This change was most noticeable at the end of the second phase of the experiment, which aimed at improving the adult females' functionality. Data on the individuals' morpho-functional status are presented in Table 2.

The dynamic analysis of the subjects' morphofunctional state indicators testifies to the effect of the authors' program of physical and recreational exercises (based on a rational combination of different fitness techniques) on the level of physical health and the development of functional capabilities in females aged 30-45 years. At the same time, the achieved positive changes do not allow to confirm reaching the expected result.

The average value of the life index for adult females should be $50-55 \mathrm{ml} / \mathrm{kg}$. In our study, the index equalled $38.2 \pm 5.1 \mathrm{ml} / \mathrm{kg}$ at the beginning of the experiment and reached $44.8 \pm 5.0 \mathrm{ml} / \mathrm{kg}(p<0.01)$ at its end. These figures indicate insufficient development of the respiratory system and excessive weight of the subjects. It is also confirmed by the value of the body mass index. Although progressively decreasing (from 28.0 
Table 1. Data of physical health level self-assessment test in adult females at different phases of the experiment $(n=32)$

\begin{tabular}{lccccc}
\hline & \multicolumn{4}{c}{ Research phases } \\
\cline { 2 - 5 } Level of health & $\begin{array}{c}\text { Beginning } \\
\text { of the experiment }\end{array}$ & End of phase 1 & End of phase 2 & End of phase 3 \\
\hline High & 2 & 2 & 3 & 3 & +3.2 \\
Above average & 5 & 6 & 9 & 10 & +13 \\
Average & 9 & 10 & 12 & 4 & -22.4 \\
Below average & 11 & 9 & 3 & 2 & -9.6 \\
Low & 5 & 5 & & 5 & +12.8 \\
\hline
\end{tabular}

Table 2. Dynamics of indicators of morpho-functional state of adult females at different phases of the experiment (mean \pm standard deviation, $n=32$ )

\begin{tabular}{|c|c|c|c|c|c|}
\hline \multirow[b]{2}{*}{ Indicators } & \multicolumn{4}{|c|}{ Research phases } & \multirow[b]{2}{*}{ Change } \\
\hline & $\begin{array}{l}\text { Beginning of the } \\
\text { experiment }\end{array}$ & End of phase 1 & End of phase 2 & End of phase 3 & \\
\hline Height (cm) & $164.5 \pm 11.5$ & $164.5 \pm 11.5$ & $164.5 \pm 11.5$ & $164.5 \pm 11.5$ & - \\
\hline Weight (kg) & $76.4 \pm 7.6$ & $74.8 \pm 8.2$ & $72.8 \pm 7.2$ & $71.2 \pm 6.5$ & $-5.2 \pm 1.1$ \\
\hline Lung capacity (ml) & $2880 \pm 70$ & $2950 \pm 90$ & $3120 \pm 80$ & $3160 \pm 90$ & $+280 \pm 20$ \\
\hline Heart rate (beats/min) & $78.5 \pm 11.5$ & $76.5 \pm 12.5$ & $73.5 \pm 11.5$ & $72.5 \pm 10.4$ & $-6.3 \pm 1.1$ \\
\hline $\begin{array}{l}\text { Systolic blood pressure } \\
(\mathrm{mm} \mathrm{Hg})\end{array}$ & $119.5 \pm 12.5$ & $115.5 \pm 11.5$ & $112.0 \pm 11.0$ & $111.0 \pm 10.0$ & $-8.5 \pm 2.5$ \\
\hline $\begin{array}{l}\text { Diastolic blood pressure } \\
(\mathrm{mm} \mathrm{Hg})\end{array}$ & $70.5 \pm 9.5$ & $70.5 \pm 10.5$ & $71.5 \pm 9.5$ & $71.6 \pm 8.5$ & $+1.1 \pm 1.0$ \\
\hline $\begin{array}{l}\text { Robinson's index } \\
\text { (standard units) }\end{array}$ & $93.5 \pm 6.5$ & $89.0 \pm 6.0$ & $83.5 \pm 6.5$ & $81.5 \pm 5.5$ & $-12.0 \pm 1.0$ \\
\hline $\begin{array}{l}\text { Ruffier-Dickson's index } \\
\text { (standard units) }\end{array}$ & $12.5 \pm 4.5$ & $10.5 \pm 4.5$ & $9.5 \pm 3.5$ & $9.0 \pm 3.0$ & $-3.5 \pm 1.5$ \\
\hline Stange’s test (s) & $29.5 \pm 8.5$ & $33.0 \pm 8.0$ & $38.5 \pm 7.5$ & $41.5 \pm 7.0$ & $+12.5 \pm 1.5$ \\
\hline Body mass index $\left(\mathrm{kg} / \mathrm{m}^{2}\right)$ & $28.0 \pm 3.3$ & $27.5 \pm 3.2$ & $26.8 \pm 2.9$ & $26.1 \pm 2.8$ & $-1.9 \pm 0.5$ \\
\hline Life index (ml/kg) & $38.2 \pm 5.4$ & $39.8 \pm 5.4$ & $43.3 \pm 5.2$ & $44.8 \pm 5.0$ & $+6.6 \pm 0.4$ \\
\hline $\begin{array}{l}\text { Recovery time after } \\
20 \text { squats (s) }\end{array}$ & $128.5 \pm 12.5$ & $122.5 \pm 12.0$ & $112.5 \pm 10.5$ & $107.5 \pm 8.5$ & $-21.0 \pm 4.0$ \\
\hline
\end{tabular}

\pm 3.3 to $\left.26.1 \pm 2.8 \mathrm{~kg} / \mathrm{m}^{2} ; p<0.05\right)$, at the end of the experiment it still implied excess weight in the subjects and the need to continue the specific workout to reduce body weight. Gradual development of the respiratory system in the adult females during the research can be verified by the dynamics of the Stange's test, which improved from $29.5 \pm 8.5$ to $41.5 \pm 7.0 \mathrm{~s}(p<0.01)$; this corresponds to the development of the respiratory system from unsatisfactory to almost good level.

The developed program of physical and recreational activities contributed to a significant improvement in the quantitative assessment of the participants' energy potential. The improvement of the Robinson's index from $93.5 \pm 6.5$ to $81.5 \pm 5.5$ standard units $(p<0.01)$ indicates a transition from an inadequate to a good level of the cardiovascular system functioning by reaching the norm for women of the corresponding age. The change of the Ruffier-Dickson's test results from $12.5 \pm 4.5$ to $9.0 \pm 3.0$ standard units $(p<0.05)$ shows improvement in the physical working capacity of the heart from a satisfactory level to intermediate and good levels. The time needed for recovery after physical activity also significantly improved: from $128.5 \pm 12.5$ to $107.5 \pm 8.5 \mathrm{~s}(p<0.001)$, which confirms positive changes in the functioning of the cardiovascular and respiratory systems.

The indicators characterizing body mass and composition determine the level of health to a large extent. The proper level of health is achieved owing to the mandatory normalization of all body mass components, which provides the necessary conditions for the normal flow of metabolic processes and thus smooth functioning of the body systems. The analysis of the body mass index and the anthropometric indicators of the 


\section{HUMAN MOVEMENT}

O. Mozolev et al., Fitness techniques in adult females

adult females showed that $59.6 \%$ of them were overweight at the beginning of the research, and $18.7 \%$ had class I-II obesity. At the end of phase 3 of the study, $34.1 \%$ of the women were overweight and $6.3 \%$ had class I obesity.

An analysis of the dynamics of anthropometric changes in the adult females during the research showed that the most significant changes occurred in the waist girth $(-5.37 \pm 2.1 \mathrm{~cm} ; p<0.01)$, hip girth $(-5.20 \pm 2.53 \mathrm{~cm} ; p<0.01)$, and bust girth $(-4.15 \pm$ $1.34 \mathrm{~cm} ; p<0.05$ ) (Table 3). It was found out that the thickness of skin folds was changing irregularly in the course of the workouts. The biggest changes occurred in the second and third phases of the workouts (training sessions). We registered a significant change in the thickness of abdominal skin folds $(-4.06 \pm$ $1.22 \mathrm{~mm} ; p<0.05)$. The endomorphic component, which characterizes the overall fat deposition, as well as the thickness of the adult females' skin folds were the biggest at the beginning of the study. The analysis of changes in the endomorphic component showed a sig- nificant difference of this indicator between the beginning and the end of the intervention $(-3.70 \pm 0.89 \%$; $p<0.05$ ).

The analysis of the physical preparedness of the adult females at the beginning and the end of the experiment implies that the use of the authors' program of integrated fitness techniques exerted a positive effect on the development of the subjects' physical abilities. The most significant changes occurred in the development of coordination abilities $(+9.3 \pm 0.7 \mathrm{~s} ; p<$ $0.001)$, high-speed endurance $(+8.3 \pm 1.7$ times; $p<$ $0.001)$, and strength endurance $(+7.4 \pm 0.2 \mathrm{~s} ; p<0.001)$. The indicators of speed-strength abilities and force development also improved significantly $(+5.5 \pm 0.8$ times; $p<0.01$ and $+5.1 \pm 0.9$ times; $p<0.01$, respectively). The indicators of speed and flexibility development changed the least $(+4.8 \pm 1.8$ steps; $p<0.05$ and $+2.7 \pm 1.7 \mathrm{~cm} ; p<0.05$, respectively) (Table 4).

The dynamics of changes in the indicators of physical preparedness of the adult females at different phases of the experiment is presented in Figure 2.

Table 3. Dynamics of indicators of anthropometric changes in adult females at different phases of the experiment (mean \pm standard deviation, $n=32$ )

\begin{tabular}{|c|c|c|c|c|c|c|}
\hline \multirow[b]{2}{*}{ Indicators } & \multicolumn{4}{|c|}{ Research phases } & \multirow[b]{2}{*}{ Change } & \multirow[b]{2}{*}{ Change (\%) } \\
\hline & $\begin{array}{c}\text { Beginning } \\
\text { of the experiment }\end{array}$ & End of phase 1 & End of phase 2 & End of phase 3 & & \\
\hline Waist girth (cm) & $86.55 \pm 9.45$ & $84.85 \pm 8.65$ & $82.45 \pm 7.85$ & $81.18 \pm 7.35$ & $-5.37 \pm 2.1$ & $-6.21 \pm 0.47$ \\
\hline Thigh girth (cm) & 65 & $3.05 \pm 5.95$ & 61.48 & 60.85 & -2.69 & -4.23 \\
\hline Hip girth $(\mathrm{cm})$ & $98.35 \pm$ & $97.42 \pm 11.13$ & $94.15 \pm$ & $93.15=$ & $-5.20 \pm 2.53$ & $-5.29 \pm$ \\
\hline Bust girth (cm) & $94.60 \pm 11.70$ & $94.25 \pm 11.15$ & $92.83 \pm$ & $90.45 \pm 10.36$ & $-4.15 \pm 1.34$ & $-4.39 \pm 0.59$ \\
\hline $\begin{array}{l}\text { Abdominal skin fold } \\
(\mathrm{mm})\end{array}$ & $36.78 \pm 7.72$ & $35.84 \pm 8.55$ & $33.28 \pm 8.05$ & $32.72 \pm 6.50$ & $-4.06 \pm 1.22$ & $-11.04 \pm 0.83$ \\
\hline $\begin{array}{l}\text { Subscapular skin } \\
\text { fold (mm) }\end{array}$ & $20.56 \pm 5.54$ & $20.22 \pm 5.27$ & $19.48 \pm 5.42$ & $18.82 \pm 5.14$ & $-1.74 \pm 0.4$ & $-8.46 \pm 0.67$ \\
\hline Thigh skin fold (mm) & $19.77 \pm 7.82$ & $19.45 \pm 7.63$ & $19.12 \pm$ & $18.82 \pm$ & $-0.95 \pm 1.0$ & $-4.81 \pm 0.36$ \\
\hline Fat percentage (\%) & $30.82 \pm 4.76$ & $30.25 \pm 4.27$ & $28.12 \pm 3.77$ & $27.12 \pm 3.87$ & $-3.70 \pm 0.89$ & $-12.01 \pm 0.81$ \\
\hline
\end{tabular}

Table 4. Adult females' physical preparedness indicators at different phases of the experiment (mean \pm standard deviation, $n=32$ )

\begin{tabular}{|c|c|c|c|c|c|}
\hline \multirow[b]{2}{*}{ Tests } & \multicolumn{4}{|c|}{ Research phases } & \multirow[b]{2}{*}{ Change } \\
\hline & $\begin{array}{l}\text { Beginning of the } \\
\text { experiment }\end{array}$ & End of phase 1 & End of phase 2 & End of phase 3 & \\
\hline Sitting forward bend (cm) & $3.5 \pm 6.5$ & $4.2 \pm 7.3$ & $5.3 \pm 7.7$ & $6.2 \pm 8.2$ & $+2.7 \pm 1.7$ \\
\hline Running in place for 10 seconds (steps) & $30.3 \pm 8.5$ & $31.7 \pm 9.5$ & $33.4 \pm 7.2$ & $35.1 \pm 6.7$ & $+4.8 \pm 1.8$ \\
\hline Rope skipping for 30 seconds (times) & $15.5 \pm 7.5$ & $18.4 \pm 8.7$ & $22.2 \pm 8.2$ & $23.8 \pm 9.2$ & $+8.3 \pm 1.7$ \\
\hline Bench push-ups for 30 seconds (times) & $4.5 \pm 3.5$ & $5.4 \pm 3.5$ & $7.8 \pm 4.2$ & $9.6 \pm 4.4$ & $+5.1 \pm 0.9$ \\
\hline Sit-ups for 30 seconds (times) & $11.2 \pm 5.1$ & $12.4 \pm 5.4$ & $15.6 \pm 4.4$ & $16.7 \pm 4.3$ & $+5.5 \pm 0.8$ \\
\hline Plank exercise (s) & $26.2 \pm 8.7$ & $28.6 \pm 8.4$ & $32.8 \pm 9.2$ & $33.6 \pm 8.8$ & $+7.4 \pm 0.2$ \\
\hline Standing on one leg (s) & $12.2 \pm 5.7$ & $15.5 \pm 6.2$ & $19.7 \pm 5.8$ & $21.5 \pm 4.5$ & $+9.3 \pm 0.7$ \\
\hline
\end{tabular}




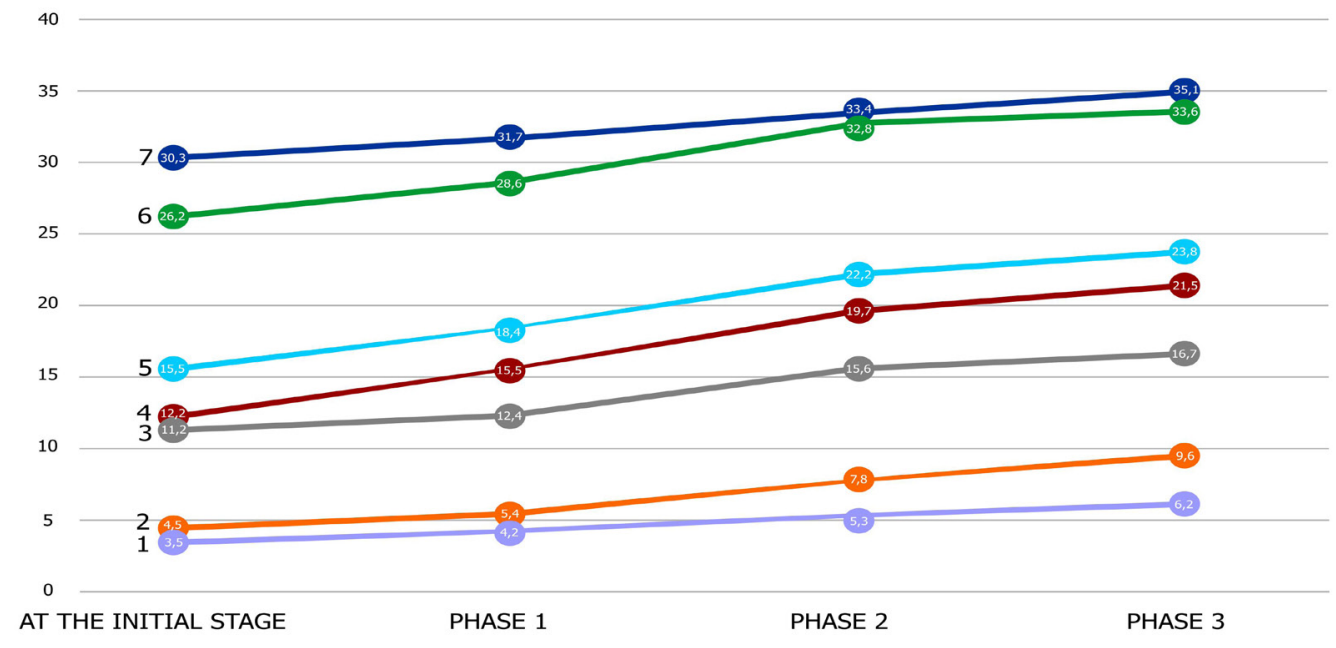

1 - sitting forward bend (flexibility), 2 - bench push-ups for 30 seconds (power), 3 - sit-ups for 30 seconds (speed-power abilities), 4 - balancing on one leg (coordination abilities), 5 - rope skipping for 30 seconds (speed endurance), 6 - plank exercise (strength endurance), 7 - running in place for 10 seconds (speed)

Figure 2. Dynamics of changes in the physical preparedness indicators of adult females at different phases of the experiment

The analysis of the adult females' physical preparedness dynamics at different phases of the experiment shows that the second phase of the research was the most productive for the development of their motor capabilities.

\section{Discussion}

The highest value for a person is health, a vital prerequisite for comprehensive and harmonious development. The issue of maintaining good health of adults is very topical for the society as adulthood is the most productive period of the human life $[11,12]$.

Solving the problems of engaging adult females in regular fitness exercises is considered by scholars from the following perspectives: proving vital necessity of active lifestyle and doing physical exercises; studying the motivation of adult females for recreational physical exercises, namely fitness; substantiation of positive changes in the health condition and well-being owing to physical activity; promotion of physical activity including various types of fitness; shifting priorities in content- and quality-based training of physical education specialists capable of implementing modern methods in physical education classes, contributing to the formation of sustainable motivation of adults for active lifestyle and systematic fitness exercises [13-16].

The analysis of our study results confirms the research on the priority of improving health status in the system of motivation for fitness exercises in adult females $[17,18]$. The obtained results expanded the data on the practical application of the methods of con- ducting physical education classes combining various modern fitness techniques, namely Pilates, shaping, and stretching $[17,18]$.

The authors proposed a program of conducting fitness sessions among adult females, which included 3 phases: health-improving, functional, and corrective workouts. The phases are logically interconnected, complementing each other. Introducing Pilates as a healthimproving type of gymnastics and its positive effect on the level of physical health of adult females have been widely elaborated [19,20]. The peculiarity of the adult females' motor activity development was the use of fitness techniques, namely shaping and stretching, which are of interest for women as they enhance their motivation to actively engage in physical exercises. Our results also expanded the research on the effect of combined training on the improvement of functional abilities, adult females' muscular system development, and body shape correction [21-23]. The study confirmed and supported the scientific views on the need for systematic assessment of the physical health level and functional status in adult females at each phase of training; such assessment allows to introduce timely changes and adjustments in the implementation of fitness activities.

\section{Conclusions}

1. In accordance with the determined value orientations of the adult females, 4 main factors influencing the motivation for doing fitness exercises have been identified: preservation and improvement of health 
(48.0\%), aesthetic appeal (22.7\%), self-confidence (11.2\%), and happy family life (10.3\%).

2 . The research revealed that the physical condition of adult females may vary greatly, which is largely depicted by different degrees of age-related changes throughout life. The health-improving effect, achieved as a result of the fitness workouts, helped to increase the level of self-esteem based on the physical condition in the adult females: $62.5 \%$ reached a higher physical condition level, while the rest of the group members noted a score increase and approached a higher level of physical condition.

3 . The analysis of the changes of the anthropometric indicators showed that $59.6 \%$ of the women were overweight at the beginning of the research, and 18.7\% had class I-II obesity. At the end of the study, 34.1\% of the subjects were overweight, and $6.3 \%$ had class I obesity.

4. By using the authors' program, combining different types of fitness exercises, it was possible to make the workouts flexible and varied, as well as to find an individual approach to each woman. This contributed to an increase of their physical condition and working capacity, having improved the functional state of the body, the physical health level, and the psycho-emotional state.

5 . The analysis of the physical preparedness of the adult females at the beginning and at the end of the experiment implies that the most significant changes occurred in the development of coordination abilities $(+9.3 \pm 0.7 \mathrm{~s} ; p<0.001)$, high-speed endurance $(+8.3 \pm$ 1.7 times; $p<0.001)$, and strength endurance $(+7.4 \pm$ $0.2 \mathrm{~s} ; p<0.001)$. The indicators of speed-strength abilities and strength development also improved significantly $(+5.5 \pm 0.8$ times; $p<0.01$ and $+5.1 \pm 0.9$ times; $p<0.01$, respectively). The indicators of speed and flexibility development changed the least $(+4.8 \pm$ 1.8 steps; $p<0.05$ and $+2.7 \pm 1.7 \mathrm{~cm} ; p<0.05$, respectively).

6. The analysis of the dynamics of the adult females' morpho-functional state indicators testifies to the effect of the authors' program of physical and recreational exercises (based on a rational combination of different fitness techniques) on the level of physical health and the development of functional capabilities in females aged $30-45$ years. At the same time, the achieved positive changes do not allow to confirm reaching the expected result yet point at the need to conduct such workouts for a longer time.

\section{Disclosure statement}

No author has any financial interest or received any financial benefit from this research.

\section{Conflict of interest}

The authors state no conflict of interest.

\section{References}

1. Tulaidan VG, Shelekhova TN. Health-improving fitness [in Ukrainian]. Lviv: FestPrint; 2016.

2. Osipov V. Optimization of the physical status of adult females by means of innovative fitness technologies [in Ukrainian]. Physical Education, Sports and Health Care in Modern Society. 2012;4(20):305-309.

3. Howley ET, Franks BD. Fitness professional's handbook. Champaign: Human Kinetics; 2007.

4. Maciaszek J, Skrypnik D, Ratajczak M, Stemplewski R, Osiński W, Bogdański P, et al. Two aerobic exercise programs in management of back pain among middle-aged obese women: a randomized controlled study. Hum Mov. 2016;17(2):72-79; doi: 10.1515/humo-2016-0016.

5. Ivaschenko LY, Blagiy AL, Usachev YA. Programming of health-improving fitness classes [in Ukrainian]. Kyiv: Naukoviy Svit; 2008.

6. Dolgova VI, Belousova NA, Mamylina NV, Vorozheykina $\mathrm{AV}$, Bogachev AN. Impact of physical activity of correctional orientation in the form of combined fitness and swimming on the psychophysiological state of 40-45-year-old women. J Phys Educ Sport. 2017;17(2): 905-909; doi: 10.7752/jpes.2017.02138.

7. Pacesova P, Šmela P, Kracek S, Plevkova J. Women's well-being, state and trait anxiety regarding their sport activity. Sport Mont J. 2018;16(2):33-38; doi: 10.26773/ smj.180606.

8. Romanchuk A, Dolgier Y. Effects of long-term training experience of aerobic exercises on middle-aged women. J Phys Educ Sport. 2017;17(2):680-687; doi: 10.7752/ jpes.2017.02102.

9. Belyak YI. Physical state of women and its dynamics under the influence of fitness training [in Ukrainian]. Sport Med. 2014;1:80-86.

10. Mosur-Kałuża S, Guszkowska M. Physical activity and body image of women: literature review. Balt J Health Phys Act. 2015;7(3):29-37; doi: 10.29359/BJHPA.07.3.04.

11. Peeters G, Dobson AJ, Deeg DJH, Brown WJ. Women's health beyond reproduction - a new agenda. Bulletin of World Health Organization. 2013;91(9):621-715; doi: 10.2471/BLT.13.000913.

12. Radas J, Sesar V, Furjan-Mandic G. Differences between female subjects practicing Pilates and aerobics. Sport Mont. 2017;15(3):25-28; doi: 10.26773/smj.2017. 10.004 .

13. Pearson ES, Hall CR. Examining body image and its relationship to exercise motivation: an 18-week cardiovascular program for female initiates with overweight and obesity. Balt J Health Phys Act. 2013;5(2):121-131; doi: 10.2478/bjha-2013-0012.

14. Mozolev O, Halus O, Bloshchynskyi I, Kovalchuk R. Human resources management of educational development in sphere of physical culture and sports in Ukraine: 
comparative analysis (1992-2016). J Phys Educ Sport. 2019;19(Suppl. 1):185-192; doi: 10.7752/jpes.2019.s1028.

15. Andrasic S, Ujsasi D, Cvetkovic M, Orlic D, Milic Z. Impact of recreational fitness training program on $\mathrm{dy}$ namic strength of women. Sport Mont. 2016;14(2):25-29.

16. Veider S. Pilates for the ideal weight [in Russian]. Rostov on Don: Fenix; 2007.

17. Cybulska A, Drobnik P. An assessment of the impact of special training of inspiratory muscles in a fitness classes program on physical capacity of 20-25-yearold women. Balt J Health Phys Act. 2015;7(4):37-47.

18. Mishchenko V, Sawczyn S, Cybulska A, Pasek M. Special training of inspiratory muscles in fitness activities and exercise capacity in young women. Hum Mov. 2017; 18(3):46-54; doi: 10.1515/humo-2017-0021.

19. Sharkey BJ, Gaskill SE. Fitness \& health. Champaign: Human Kinetics; 2006.

20. Plachy JK, Kovách MV, Bognár J. Improving flexibility and endurance of elderly women through a six-month training programme. Hum Mov. 2012;13(1):22-27; doi: 10.2478/v10038-011-0050-6.

21. Lehnert M, Stastny P, Sigmund M, Xaverova Z, Hubnerova B, Kostrzewa M. The effect of combined machine and body weight circuit training for women on muscle strength and body composition. J Phys Educ Sport. 2015;15(3):561-568; doi: 10.7752/jpes.2015.03084.

22. Saeidi A, Tayebi SM, Khosravi A, Razi O, Sellami M, Ben Abderrahman A, et al. Obesity, fat mass, osteopontin and exercise training. Int J Appl Exerc Physiol. 2019; 8(1):177-179; doi: 10.30472/ijaep.v8i1.372.

23. Sheikhian N, Ostovan MA, Daryanoosh F, Sharifi F. Aerobic exercise improves brain natriuretic peptide and C-reactive protein among men and women with coronary artery disease. Int J Appl Exerc Physiol. 2018;7(4):30-40; doi: 10.30472/ijaep.v7i4.309. 